\title{
La ruta psicosocial del desplazamiento: una perspectiva de género*
}

\section{Psychosocial Pathway of Displacement: A Gender Perspective}

Recibido: diciembre 27 de 2012 | Revisado: septiembre 20 de 2013 | Aceptado: octubre 20 de 2013

\author{
AMALIO BLANCO ** \\ Universidad Autónoma de Madrid, España \\ MARÍA AMARÍs *** \\ Universidad del Norte, Barranquilla, Colombia
}

doi:10.11144/Javeriana.UPSY13-2.rpdu

Para citar este artículo: Blanco, A. \& Amarís, M. (2014). La ruta psicosocial del desplazamiento: una perspectiva de género. Universitas Psychologica, 13(2), 661-679. doi:10.11144/Javeriana.UPSY13-2. rpdu

* Esta investigación ha sido llevada a cabo en el marco del proyecto PSI2009-12108 del Ministerio español de Ciencia e Innovación.

** Catedrático de Psicología Social. Universidad Autónoma de Madrid. Facultad de Psicología. Correo electrónico: amalio.blanco@uam.es

**** Correo electrónico: mamaris@uninorte.edu.co

\section{RESUMEN}

Con cerca de cuatro millones de personas afectadas, el desplazamiento forzado constituye hoy en día uno de los mayores problemas sociales a los que se enfrenta la sociedad colombiana. Alrededor de la mitad de estos cuatro millones son mujeres. Este artículo toma como punto de partida varios estudios realizados en los últimos años en el Departamento de Psicología de la Universidad del Norte (Barranquilla) utilizando una metodología cualitativa (8 grupos focales con mujeres desplazadas). Fruto de estos estudios es la conclusión de que la experiencia del desplazamiento en las mujeres está claramente marcada por una ruta que tiene los siguientes episodios: a) la añoranza de la vida en el campo; b) la intempestiva llegada de la violencia y la decisión de huir; c) la vida en la ciudad de acogida y d) la esperanza en el futuro.

Palabras clave

Desplazamiento, género, violencia, trauma, trastorno de estrés postraumático.

\section{A B S T R A C T}

With approximately four million affected people, forced displacement is nowadays one of the largest social problems Colombian society must face. About half of these four million are women. This article uses various studies carried out in the last years at the Psychology Department of the Universidad del Norte (Barranquilla) based on qualitative methodology ( 8 focal groups with displaced women) as a starting point. As a result of these studies it is concluded that the experience of displacement is clearly marked by a route that includes the following episodes: a) yearning for country life; b) the untimely arrival of violence and the decision to escape; c) life in the city of acceptance, and d) hope in the future.

Keywords

Displacement, gender, violence, trauma, PTSD. 
El desplazamiento forzado es un fenómeno en alza en el mundo actual. El Alto Comisionado de Naciones Unidas para los Refugiados (ACNUR) ofrece datos estremecedores: a finales de 2011, el número de personas desplazadas contra su voluntad superaba los 42 millones. De ellas, 15.2 millones son refugiados, 26.4 son desplazados internos y 859.000 los solicitantes de asilo. Este desalentador cuadro se completa con los 4.8 millones de refugiados palestinos bajo la responsabilidad de la UNWRA (Agencia de Naciones Unidas para los Refugiados Palestinos). El año 2011 fue especialmente dramático: los conflictos en Costa de Marfil, Libia, Somalia y Sudán "forzaron a más de 800.000 refugiados a huir a los países vecinos, la cifra más alta en más de una década" (ACNUR, 2011, p. 5). Y posiblemente el año 2012 no lo será menos, debido a la huida masiva de ciudadanos sirios.

Con 3.888.309 desplazados internos a finales de 2011, según datos de ACNUR (2011), Colombia ocupa un triste puesto de honor en esta desgarradora historia por delante de Sudán (2.422.520) e Irak (1.332.382). Las razones que están detrás de estas alarmantes cifras han venido siendo investigadas y analizadas desde hace dos décadas. La más común apunta al enquistado conflicto armado que ha enfrentado desde finales de la década de los cuarenta a diversos grupos guerrilleros con el gobierno (Consultoría para los Derechos Humanos y el Desplazamiento [Codhes], 1999; Conferencia Episcopal, 1995; Rojas, 1993) "con la consiguiente violación de los derechos humanos y transgresiones al derecho internacional humanitario" (Conferencia Episcopal, 1995, p. 14). A la disputa territorial de los actores armados, Marta Bello, una de las más sólidas investigadoras en este campo, añade la confluencia de la ancestral pobreza y exclusión del campesinado con las presiones derivadas del modelo neoliberal y el mercado de los cultivos ilícitos (Bello, 2004a, p. 21), con la influencia del narcotráfico en la concentración de la tierra, en una palabra (Castillo, 2004). Contrastadas todas estas hipótesis mediante modelos de correlación y de regresión lineal, Luis Eduardo Pérez (2004) viene a concluir que son las condiciones de inequidad, y sobre todo el potencial económico (capacidad de generar nuevas riquezas) de los municipios expulsores, que disponen de un 179\% más de potencial para generar riqueza que los no expulsores, las razones que están detrás del desplazamiento. Sea como fuere, este hecho pone de nuevo en el centro del debate "la histórica discusión del conflicto agrario, la tierra y el territorio, vinculándolo al marco de los derechos humanos de las víctimas del conflicto" y provocando una intensa crisis humanitaria y de derechos humanos que afecta ya a más del 10\% de la población colombiana (ACNUR, 2011, p. 31).

Hablamos, pues, de un delito de lesa humanidad que conduce a personas inocentes a una experiencia traumática de consecuencias psicológicamente destructivas y socialmente desestabilizadoras, como ha sido puesto de manifiesto en diversos estudios a lo largo de las últimas dos décadas (Abello et al., 2009; Alejo, Rueda, Ortega \& Orozco, 2007; Amarís, 2012; Aristizábal \& Palacio, 2003; Bello, 2004b; Bello, Martín \& Arias, 2000; Castaño, 1994; Médicos Sin Fronteras, 2010; Palacio, Abello, Madariaga \& Sabatier, 1999; Palacio \& Sabatier, 2002, entre otros. Ver asimismo los monográficos que Universitas Humanística y la Revista de Estudios Sociales dedicaron en 1999 y 2010 al desplazamiento y a la atención psicosocial en el conflicto armado, respectivamente). Y si tenemos en cuenta que el origen de este fenómeno se inscribe, de manera preferente, en una sostenida situación de violencia que enfrenta a grupos en conflicto, o en una persecución implacable y cruel contra gentes y poblaciones a las que se quiere expulsar de su territorio, no deberíamos albergar duda alguna respecto a su naturaleza: se trata de una experiencia traumática en toda regla ya que la vida, la integridad física, la seguridad o la libertad de las personas "han sido vulneradas o se encuentran directamente amenazadas con ocasión de cualquiera de las siguientes situaciones: conflicto armado interno, disturbios y tensiones interiores, violencia generalizada, violaciones masivas de los derechos humanos, infracciones al Derecho Internacional Humanitario", entre otras circunstancias. Esta definición que hace el Estado colombiano de la persona en situación de desplazamiento (Ley 387 de 1997) cumple de manera cabal los requisitos más importantes que el DSM-IV contempla en la 
definición del trastorno por estrés postraumático (TEPT): exposición a un hecho estresante que "representa un peligro real para su vida o cualquier otra amenaza para su integridad física” (American Psychiatric Association [APA], 2002, p. 518) ${ }^{1}$ y donde la muerte violenta se convierte en un hecho cotidiano, en un acontecimiento común. Todavía más, cabría considerar este acontecimiento como especialmente traumático por ser el "el agente estresante obra de otros seres humanos" (APA, 2002, p. 519). En los episodios que han jalonado esta trágica historia, las mujeres han sido por lo general las víctimas más propiciatorias.

\section{Experiencia traumática y género}

El género ha sido ampliamente reconocido como una variable empírica importante a la hora de abordar el estudio de muchos procesos psicológicos, desde el rendimiento en matemáticas hasta la vulnerabilidad ante eventos traumáticos, pasando por la expresión de las emociones, la autoestima, o el desarrollo de la empatía, el altruismo o la compasión (Stewart \& McDermott, 2004). En el caso de las experiencias traumáticas y, más en concreto, de la prevalencia del TEPT, las diferencias de género están ampliamente documentadas en estudios llevados a cabo en momentos, países, culturas y eventos distintos (ver a este respecto las revisiones epidemiológicas de Norris, Foster \& Weissharr, 2002; Norris \& Sloane, 2007; Norris et al., 2002). Los estudios llevados a cabo con población general adulta en Estados Unidos (Kessler, Sonnega, Bromet, Hughes \& Nelson, 1995), Australia (Creamer, Burgess \& McFarlane, 2001) y Canadá (Stein, Walker, Hazen \& Forde, 1997), todos ellos con muestras representativas de la población general, muestran, al menos, cuatro coincidencias muy significativas: a) la experiencia de eventos traumáticos

1 La inminente edición del DSM-V introduce una diferenciación entre acontecimiento traumático y acontecimiento estresante, pero mantiene como primer criterio (A1) el que la persona haya estado expuesta a muerte, amenaza o peligro de daño grave. A ello añade la violación sexual real o como amenaza. Todo ello bien en primera (experimentar uno mismo el acontecimiento) o en tercera persona (ser testigo o tener conocimiento de esto). entre la población adulta es muy frecuente; b) la persistencia del TEPT es muy reducida (alrededor del 8\% en el National Comorbidity Survey (Kessler et al., 1995); c) la probabilidad del TEPT varía de acuerdo con el evento estresante: es mucho mayor como consecuencia de eventos intencionalmente perpetrados por la mano del ser humano (violencia política, violencia de género) que cuando proviene de accidentes naturales; d) aunque son los hombres los que están expuestos a lo largo de su vida a un mayor número de eventos traumáticos (el 60.7\% frente al $51.2 \%$, el $64.5 \%$ frente al $49.5 \%$ y el $82 \%$ frente al 74.2\% en Estados Unidos, Australia y Canadá, respectivamente, según los datos de las investigaciones citadas), son las mujeres las que corren el mayor riesgo de desarrollar un TEPT (el 20.4\% frente al $8.1 \%$, y el $8.2 \%$ frente al 1.8\% en los estudios de Estados Unidos y Canadá). Por otra parte, no todos los estudios (160) que forman parte de la revisión de Norris, et al. (2002) incluyen la variable género. De los que lo hacen, 49 señalan una diferencia estadísticamente significativa de esta variable en las reacciones de estrés, ansiedad o trastorno y en 94\% de ellos se encontró una mayor incidencia de los efectos postraumáticos en las mujeres, unas secuelas más negativas, una mayor repercusión sobre su salud mental, tanto en la adolescencia como en la edad adulta y tanto en Estados Unidos como en países en desarrollo. De acuerdo con estos estudios, la probabilidad de desarrollar un TEPT es alrededor de dos veces mayor en las mujeres (Norris et al., 2002, p. 229). Tan solo hay una excepción: el abuso del alcohol a raíz de un evento traumático es mucho más frecuente en los hombres.

Si nos centramos en el contexto latinoamericano, un estudio llevado a cabo con 267 excombatientes de los grupos que lucharon frente a frente en la guerra civil de El Salvador (la guerrilla del FMNL y el ejército) muestra una prevalencia del TEPT, de acuerdo con las respuestas a la Escala de Síntomas de Davidson, del 53.6\%; el 71\% de todos los casos son mujeres (Flores, Molina \& Valle, 2010). En los estudios de Vázquez, Ibáñez y Murguialday (1996), Las Dignas $(1996,1997)$ o Yáñez (2010) no hay datos comparativos, pero en los relatos que las mujeres hacen están presentes, 
de manera muy generalizada, el hostigamiento, el acoso y la agresión sexual, la violación, el abuso de poder y la sumisión frente al hombre. En el primero de ellos se analiza, mediante una metodología cualitativa con grupos focales en los que participaron 60 mujeres "los cambios ocurridos en la vida cotidiana y la subjetividad de las mujeres que participaron en la guerra" prestando una especial atención a su impacto "en la subjetividad femenina, y particularmente, en torno a las vivencias sexuales, reproductivas y maternales" (Vázquez et al., 1996, p. 22). Entre los costes emocionales de la guerra, se encuentra la violencia sexista que llegó a alcanzar "niveles nada despreciables en las filas del FMLN” (Vázquez et al., 1996, p. 246), y junto a ella, el recuerdo de las persecuciones de que fueron objeto por parte del ejército, la soledad emocional que tuvieron que soportar, la separación de los hijos, la escasa valoración de su actividad. A la postre, y a pesar del balance positivo que la mayoría de ellas hacen, "muchas mujeres han sido víctimas de traumatización extrema y sufren actualmente las secuelas de los duelos no elaborados por las pérdidas de sus familiares, por las violaciones sufridas y por la desesperación de haber vivido tanto sufrimiento" (Vázquez et al., 1996, p. 246). La investigación realizada en cuatro ciudades mexicanas (Oaxaca, Guadalajara, Hermosillo y Mérida) con una muestra de 2.509 adultos (Norris et al., 2003) ofrece resultados de gran interés dadas las semejanzas socioculturales con el contexto en el que se han desarrollado los estudios que presentamos en este artículo. La exposición a eventos traumáticos (criterio A1 del DSM-IV) es manifiestamente mayor (estadísticamente significativa) entre los hombres (83\%) que entre las mujeres (71\%); sin embargo, el desarrollo del TEPT se eleva al $21 \%$ en las mujeres frente al $9 \%$ en el caso de los hombres. A la postre, las mujeres tienen dos veces más probabilidad de desarrollar un trastorno (15\%) que los hombres (7\%). Por otra parte, en las mujeres hay una alta prevalencia del TEPT crónico (un 7\%), debido, en buena medida, a la recalcitrante presencia de la violencia que acaba por convertirse en el factor de riesgo más importante. El Informe que el Arzobis- pado de Guatemala da a conocer sobre la represión política dedica un capítulo a la violencia contra las mujeres (Proyecto Interdiocesano de Recuperación de la Memoria Histórica [REMHI], 1998, Vol. 1, pp. 203-237), porque las actuaciones de los cuerpos represivos incluían "formas de violencia específica" tales como la separación de sus hijos, la violación particular y las violaciones masivas, la extracción violenta del feto a las embarazadas, cocinar y bailar para los victimarios, etc. "En el interminable listado de vejaciones, humillaciones y torturas que las mujeres padecieron, la violación sexual ocupa un lugar destacado, por ser uno de los hechos crueles más frecuentes y que reúne unos significados más complejos en cuanto a lo que representa como demostración de poder para el victimario, y de abuso y humillación para quien la sufre" (p. 210). Aunque no hay datos comparativos y la información sobre la vivencia traumática de las propias víctimas no es muy profusa, se sabe que como consecuencia de la violación el 60\% de las mujeres han quedado psicológicamente afectadas (p. 218).

Por lo que respecta a Colombia, la mirada de género en el estudio del desplazamiento forzado no ha sido la más frecuente, pero cuando se ha tomado en cuenta, el panorama que se nos ofrece (Duque, 2000; Grupo de Psicología Social Crítica, 2010; Meertens, 2004; Palacio \& Sabatier, 2002; Wilches, 2010, entre otros) no dista mucho del que se perfila en otros países del entorno. Meertens (2004) hace el siguiente balance: a) los hogares monoparentales regidos por mujeres a causa de la violencia (pérdida del marido o compañero por asesinato) alcanza el 49\%; b) la destrucción, el desarraigo, la ruptura de los lazos vitales suelen ser especialmente intensas y dolorosas para las mujeres campesinas, ya que su vida había estado más vinculada "a las relaciones primarias de la familia, lo doméstico, la vecindad" (p. 200) y una menor participación en la esfera pública; c) las mujeres, en una medida parecida a los hombres, sufren el estigma de ser desplazadas; d) sin embargo, participan de manera escasa en la interlocución institucional y, finalmente, e) se muestran más vulnerables que los hombres a la violencia de género y a la violencia sexual, un arma 
tradicionalmente utilizada en todos los escenarios en conflicto.

Algo parecido reflejan las diversas investigaciones realizadas en Palestina, particularmente en la franja de Gaza (Giaconia et al., 1995; Giacaman, Shannon, Saab, Arya \& Boyce, 2007; Kolltveit et al., 2012), en Ruanda (Neugebauer et al., 2009), en Bosnia-Herzegovina (Smith, Perrin, Yule, Hacam \& Stuvland, 2002) y en Somalia, donde el 29.7\% de las mujeres somalíes que acudían a un Centro de Salud Primaria en Mogadiscio después de las revueltas violentas de 2009, mostraban síntomas claros de padecer un TEPT en comparación con el 14-17\% de la población general (De Jong et al., 2011), ello a pesar de que los excombatientes eran predominantemente hombres.

A pesar de las apariencias, el interés que han despertado los 42.5 millones de refugiados en la corriente mayoritaria de la psicología ha sido escaso. Este artículo pretende hacer una modesta aportación en este terreno. Su principal objetivo consiste en obtener información sobre los pasos que han dado, las rutas que han seguido y los caminos que han transitado en su vida y experiencia personal y en sus relaciones familiares y sociales un grupo de mujeres desplazadas desde su vida en el campo hasta su actual situación en la ciudad de acogida. Lo queremos hacer, como no podía ser de otra manera, desde una perspectiva de género; es decir, entendiendo que los escenarios sociales y culturales juegan un papel decisivo en, al menos, los tres siguientes procesos: a) en la dinámica de las relaciones de poder que se dan en el marco de las interacciones entre hombres y mujeres; b) en la definición y el aprendizaje de las tareas y cometidos (roles sociales) esperados, encomendados y/o exigidos a cada uno y c) en la existencia de ambientes y escenarios adversos, tanto durante la vida en el campo como en el lugar de acogida tras el desplazamiento. En definitiva, la perspectiva de género "describe una serie de relaciones de poder en las que, ausentes otras condiciones, masculinidad significa autoridad, estatus, competencia, poder social e influencia, y femineidad indica falta de autoridad, bajo estatus, incompetencia y poder e influencia escaso" (Stewart \& MacDermott, 2004, p. 521).

\section{Método}

\section{Participantes y procedimiento}

El presente artículo es fruto de tres estudios llevados a cabo en los últimos años en el Departamento de Psicología de la Universidad del Norte en colaboración con la Unidad de Atención y Orientación al Desplazado (UAO). En estos estudios ha participado un total de 53 mujeres con una media de edad de 43 años y residentes en el barrio de Loma Roja (25) y en el municipio de Soledad (28), cerca de la ciudad de Barranquilla. Este grupo de mujeres comparten, al menos, las siguientes características: a) todas ellas proceden de entornos campesinos que han sufrido las embestidas de la violencia y ello les ha obligado a desplazarse; b) su nivel de escolaridad, en la mayoría de los casos, se limita a la escuela primaria; c) viven en entornos empobrecidos, insalubres y muy inseguros; d) todas ellas están casadas o viven o han vivido en pareja; e) la inmensa mayoría ha sufrido violencia en sus relaciones de pareja y e) su desempeño profesional actual suele estar ligado, de manera preferente, a trabajos informales como empleadas domésticas, atender tiendas en sus casas, etc. Estas 53 mujeres conformaron ocho grupos focales, cuatro en Soledad y cuatro en Loma Roja²

La técnica del grupo focal está pensada de manera preferente "para obtener información sobre la forma en que estructuran sus percepciones y su discurso los sujetos participantes" (López \& Scandroglio, 2007, p. 584) en torno a temas y cuestiones que, de acuerdo con la tradición teórica sobre el tema de estudio y de las investigaciones previas, resultan centrales. En la Tabla 1 se recogen los temas previamente escogidos y ordenados de antemano que requiere la técnica de grupos focales (Krueger, 1991). Todas las reuniones fueron grabadas y posteriormente transcritas.

2 En los resultados se ofrecen testimonios de cada uno de los grupos focales que corresponden a las siguientes siglas: GF1,2,3,4S son los grupos de mujeres que viven en el municipio de Soledad, y GF1,2,3 y 4LR corresponden a mujeres que viven y participaron en los grupos focales del barrio de Loma Roja. 
TABLA 1

Guión de los grupos focales con mujeres desplazadas

\begin{tabular}{|c|c|c|c|}
\hline La vida en el campo & La llegada de la violencia & $\begin{array}{c}\text { La vida en la ciudad de } \\
\text { acogida }\end{array}$ & El futuro \\
\hline $\begin{array}{l}\text { Las tareas cotidianas. } \\
\text { Relaciones al interior de la } \\
\text { familia (hijos y pareja). } \\
\text { La relación con los vecinos. } \\
\text { Las fiestas y celebraciones } \\
\text { familiares. } \\
\text { Las fiestas y celebraciones } \\
\text { colectivas. }\end{array}$ & $\begin{array}{l}\text { Presencia en su comunidad } \\
\text { de grupos armados. } \\
\text { Actividad de los grupos } \\
\text { armados. } \\
\text { Experiencias personales, } \\
\text { familiares y/o comunitarias } \\
\text { de violencia. } \\
\text { Vida familiar y comunitaria } \\
\text { durante la violencia. }\end{array}$ & $\begin{array}{l}\text { La decisión de desplazarse. } \\
\text { Adaptación a la vida en la } \\
\text { ciudad. } \\
\text { Condiciones de vida en la } \\
\text { ciudad. } \\
\text { Actividades a las que se } \\
\text { dedican. } \\
\text { Vida familiar. } \\
\text { Vida de pareja. } \\
\text { Vida social. }\end{array}$ & $\begin{array}{l}\text { Proyecto de vida. } \\
\text { Sueños para el futuro pro- } \\
\text { pio. } \\
\text { Sueños para el futuro de sus } \\
\text { hijos. } \\
\text { Deseo de volver a la vida en } \\
\text { el campo. }\end{array}$ \\
\hline
\end{tabular}

Fuente: elaboración propia

\section{Resultados}

Los relatos que se van poniendo en común a lo largo de las reuniones de los grupos focales tienen, como era de esperar, perfiles muy particulares, describen experiencias y vivencias muy personales que son asimismo fruto de historias de vida singulares a las que no son ajenos, sin embargo, rasgos y características comunes capaces de ofrecernos una visión panorámica de un acontecimiento tan complejo y tan plagado de matices que acabarían por dibujar una historia de añoranzas por lo perdido, de heridas dejadas por la violencia colectiva, de sufrimiento por las duras condiciones de vida que impone la situación de desplazamiento, que afortunadamente se ve acompañado de un rayo de esperanza en el futuro.

\section{La "apacible" vida en el campo}

La vida de la inmensa mayoría de las personas que actualmente se encuentran en situación de desplazamiento ha echado sus raíces en escenarios campesinos, se ha desarrollado en continuo contacto con la naturaleza, ha estado acompañada de un gratificante sentimiento de libertad (posibilidad de andar de un sitio a otro sin restricciones) y de seguridad, se ha visto rodeada de los seres queridos y ha discurrido en buena sintonía con la comunidad. Era una vida apacible, calmada, amena incluso, y plenamente dedicada al cultivo de la tierra y a la cría de animales, preferentemente para la manutención de la familia:

Vivíamos en la finca y criábamos animales (...), y pues no teníamos problemas ni con la violencia ni (...) de que robaban aquí ni que de pronto mataran a un vecino tuyo, ni anda de eso. Éramos un pueblo pacífico. Era tranquilo, o sea, nosotros salíamos a hablar tarde en la noche, en las puertas hablando y no se tenía miedo de nada (...). (GF2S)

Esa vida "apacible" daba comienzo antes de salir el sol y exigía dedicación exclusiva, disciplina y sacrificio. Las mujeres se levantaban junto con sus hijas mayores para preparar el desayuno de los hombres (moler el café, preparar la masa para las arepas, cocinar la yuca), hacer la limpieza de la casa y/o de la finca y dar de comer a los animales. Por su parte, los hombres y los hijos varones enrejaban las vacas, las ordeñaban, guiaban el ganado y dedicaban el resto del tiempo al trabajo en el campo. Todo perfectamente organizado de acuerdo con una clara y metódica división de roles siguiendo las pautas de la más rancia tradición campesina, que va conformando así un sólido aprendizaje y reproduciendo modelos diferenciales de socialización que se interiorizan con la etiqueta de leyes naturales y se muestran muy impermeables al paso del tiempo.

Ah, bueno, mientras ellos ordeñaban, nosotras pelábamos la yuca para todos los trabajadores. Cuando venían a las siete de la mañana desayunaban e iban 
a trabajar junto al campo. Regresaban a las cuatro de la tarde. Después a las ocho tenía que estar listo el desayuno que ellos se fueran. A las doce hacer el almuerzo pa' que ellos, pa' llevarlo pa' onde estaban ellos, y a las cuatro cuando ellos venían estuviera ya este, la cena lista pa' servirle pa' que ellos se fueran pa' sus casas con la familia. (GF4LR)

En la finca, él [el varón] ordeñaba y yo a veces así cuando llegaba yo le daba la comida, y también ahí en la finca le ayudaba. (GF2LR)

Esta visión que las mujeres desplazadas tienen de su vida en el campo se completa con alusiones llenas de añoranza a un tema de gran relevancia psicológica: el confortable sentimiento de apego, pertenencia, seguridad y apoyo procedente del entorno familiar al que se añade la confianza, solidaridad y cooperación procedente de amigos y vecinos. Ambas definen una estructura de lazos vitales muy sólidos y muy gratificantes. Si esa es o no una visión idílica no hay forma de contrastarlo; vale saber que así lo perciben las mujeres que en la actualidad se encuentran en situación de desplazamiento. Este es, quizás, el sentimiento más hondo, y, por tanto y al mismo tiempo, la pérdida más sensible en su nueva situación. La invocación a las fiestas familiares, con sancocho, ron y vallenato, a las celebraciones religiosas, a la participación en actividades conjuntas, es recurrente entre las mujeres que han participado en nuestros estudios y forma parte de la misma experiencia:

Allá los vecinos eso eran iuf! Uno siempre hablaba con ellos, se pasaba que si la comida, que si el poquito de ñame, de sopa, que si el tinto por la mañana. Los vecinos nos ayudábamos unos a otros, a veces si no teníamos le decíamos a la vecina de al lado y enseguida [nos regalaba; nos prestaba]. (GF4LR)

En las tardes yo, yo no quería comer arroz, por ejemplo, quería unos patacones, y yo hacía patacón, pero sin en cambio mi hija quería arroz, yo llegaba donde la vecina: 'regálame un pocillito de arroz". Y llegaba, y así y todo. (GF2S)
Pero esta añoranza de la comunidad se deja acompañar por unas condiciones materiales de vida muy deficientes (casas de palma, muchas de ellas sin electricidad y sin agua corriente, ausencia de servicios públicos, de transporte, etc.), escasas posibilidades de formación, limitados recursos económicos para satisfacer las necesidades básicas, estructura familiar dominada por la incontestable figura (autoridad) del padre y por la obligada sumisión del resto de los miembros de la familia y por unas actitudes muy discriminatorias respecto a la mujer que, en muchos casos, acaban desembocando en violencia de pareja. Todos estos ingredientes forman parte también de la vida en el campo. De entre todos ellos, merece una especial atención la presencia obstinada de la violencia de género en las vidas de estas mujeres.

Es un secreto a voces, pero no sale a la luz de manera espontánea. Todo lo contrario: en los grupos focales los temas relacionados con la violencia contra la mujer por parte de sus parejas se evitan y se esconden bajo el silencio y la reserva. La vergüenza y el miedo a ser señalada (estigmatizada) como una mujer maltratada son algunas de las razones para intentar ocultar lo que es de dominio público. Dichas razones son debidas, en parte, a la generalizada creencia de que "eso es por algo", en estrecha sintonía con esa ilusión psicológica de que el mundo en el que vivimos tiene su lógica (es un mundo justo) y pone a cada uno en el sitio que le corresponde. En último término, las víctimas se hacen acreedoras de esa situación. Cuando se hace presente la violencia en la relación de pareja, es porque "algo les faltaba o porque no sabían hacer como cocinar, lavar bien, atender bien al marido o a los hijos". Sin embargo, y a pesar de las reticencias a abordar abiertamente este tema, cuando encuentra su cauce de expresión y logra romper los diques del pudor y la vergüenza, se van poniendo de manifiesto algunos extremos de gran interés.

En primer lugar, es de dominio público que muchos hombres acostumbran a maltratar a sus mujeres, y que esa actitud viene de lejos, de la quizás no tan plácida vida en el campo. Por otra parte, el tipo de maltrato más frecuente no es el maltrato físico, sino el verbal: el rechazo, los insultos, las descalificaciones, 
la humillación, la comparación con otras mujeres ("tú no sirves para nada"; "estoy así es por ti"; "en mala hora me fui a vivir contigo"). Se dan también frecuentes episodios de maltrato sexual (obligar bajo la fuerza a ciertas prácticas sexuales a las que las mujeres no querían acceder). Todo ello, animado muchas veces, sobre todo a la vuelta a casa por la tarde-noche, por el alcohol (el 'guandolo'), se expresa públicamente en presencia de los hijos, quienes no solo son testigos de la violencia, sino receptores directos de ella:

La primera vez fue una vez que estaba con la regla y él llegó borracho a tener relaciones sexuales, y yo no quería porque tenía mucha sangre. Entonces me pegó. (GF3S)

Les pega [el padre] con una correa. Les grita. Les dice un poco de cosas. A la niña mía un día la jaló de los pelos. (GF1LR)

José se la pasaba era bebiendo, y ahora con el guandolo ese y to' lo que coge se lo gasta es en ron, y otra vez se puso altanero, a gritarme, a amenazarme con el palo que me iba a dar. (GF3S)

El machismo y la puesta en práctica de esquemas pertenecientes a una cultura del honor han definido las pautas de las relaciones de pareja en tres aspectos que han marcado la vida de la mayoría de estas mujeres: a) inicio muy temprano de la convivencia en pareja y, lo que es todavía peor, de la maternidad; b) escasa o nula formación y educación sexual y c) reproducción de modelos de relación basados en la dinámica poder-sumisión:

Yo me vine a vivir con el señor a los 14 años. $\mathrm{Al}$ año de vivir juntos ya me pegaba porque yo no sabía hacer nada, por cualquier cosa me pegaba. La familia de él me defendía, pero la mía no. (...) Pedro hacía conmigo lo que quería y mi papá y mi mamá no hacían sino darle el lao a él. La verdad es que a mí no me importaba mucho, eso era cosa de todos los días y yo me aguantaba. (GF2LR)

Yo sí he visto y he vivido la violencia. Yo tenía 15 años y él 28. Yo vivía en Malambo ipero eso era puro golpe! Él era muy celoso hasta con mis hermanos. Me dejaba cerrada con candao', no tenía derecho a salir. Al comienzo me trataba bien, pero después salí embarazada. iiUff!! De una golpiza me hizo sacar el bebé. Yo le tenía miedo. No me defendía. Él era muy agresivo. (...) Mi familia no sabe, él siempre me golpeaba, me golpeaba feo. (GF1S)

Nunca me hablaron de la menstruación. Yo me formé a los 13 años y no sabía lo que era eso. Eso fue un día que me vi el pantaloncito sucio de sangre y pensé que estaba enferma. Le dije fue a mi hermano y él me dijo que no le dijera a nadie, pero como yo no sabía lavar bien, mi mamá se dio cuenta. (GF1S)

\section{La llegada de la violencia}

En un determinado momento de sus vidas, y sin previo aviso, a esta silenciosa y pertinaz violencia en el seno de la pareja se le añade una violencia mucho más visible, más destructiva, más dolorosa, más incomprensible, que irrumpe en la cotidianeidad de la vida campesina como un huracán devastador. Hacen acto de presencia los grupos armados e inician una campaña de terror matando de manera indiscriminada, intimidando, amenazando y extorsionando con el propósito de desalojar a los campesinos de sus tierras.

Pura zozobra. (...) Todos los días se sobrevivía. (...) Pero todos los días ver muertos, o sea, al menos yo me sentía bien con Dios, pero era tanta la desolación y el miedo que una noche me tocó salirme de la casa porque no aguantaba, era algo tremendo (...) porque en la noche ya se ponía más (...) porque por el día no le da tanto nervio, pero cuando se hace las seis de la tarde y esos perros ladraban (...). (GF2LR)

Uno vivía con los problemas, pero uno vivía. Cuando eso empezó a ponerse maluco que eso le decían a uno que mataban por un lao', que mataban al poco de gente por otro lao, que uno no sabía ya ni quién era quién y no podía ni abrir la puerta de la casa. (GF1S)

Desde comienzos de la década del 2000, las familias empiezan a ser víctimas de ataques per- 
sonales, destrucción de sus cultivos y propiedades, desapariciones, masacres, toma de pueblos, extorsiones: "cuando eso [la violencia] empezó como en el 2000, nosotros tuvimos un encuentro en el que mataron a un poco de paramilitares. Esa historia también la viví yo". Todo ello se salda con la muerte de miles de campesinos por el mero hecho de "estar allí", un decisivo e inesperado factor de riesgo de la experiencia traumática que ha pasado desapercibido en la literatura especializada al uso. Todas las mujeres que han actuado como co-investigadoras en estos estudios han sido testigos directos de algunos (o de varios) de estos acontecimientos, y muchas de ellas los han sufrido además en sus propias carnes: muertes de familiares, vecinos, desaparición de hermanos, hijos, etc.

A nosotros nos pasaron varios percances, no solamente que nosotros vinimos acá porque él [el esposo] estaba amenazao' y ya, pero no. Nosotros estábamos con los pelaos en el monte y todo era bueno, cuando ya comenzó a venir el grupo. A nosotros nos atracaban. (...) Llegaban encapuchados, llegaban a veces guerrilla, a veces no era guerrilla, a veces eran los paramilitares, entonces uno vivía con sobresalto. (GF3LR)

A él [una madre habla del asesinato de su hijo] lo mataron y lo ahorcaron. A él le amarraron las manos, los pies y la pasaron la cabuya por aquí, o sea que no podía moverse. Porque entonces, cuando lo mataron, menos mal que no lo echaron por ahí por el monte. Lo sacaron a las carretera y lo mataron ahí; lo arrodillaron. (GF1LR)

(...) se lo llevaron y se lo llevaron y al final lo mataban a personas sin unos saber por qué, por qué mataron a fulanito si era buena persona, honrada, trabajadora, y uno no sabía el motivo por el cual ellos mataban. Ese era el miedo de uno, porque si uno desde hace tiempo se conocía y sabía sus cualidades que eras honrada y eso, y si fulano nunca ha sido mala gente porque llegaron y lo mataron. Uno se ponía a pensar todo eso, pero nunca se escucharon rumores. Llegaban, los sacaban y a muchos los mataban. (GF4S)
Este nuevo estado de cosas quiebra la tranquilidad, el sosiego y la paz de la vida campesina, introduce entre sus habitantes el miedo a los desconocidos, la desconfianza respecto a los conocidos, el temor a hablar en público; reduce la libertad de movimiento, aleja a la gente de la participación en actividades comunitarias y los devuelve, temerosos, al interior de sus modestas viviendas apenas se ha puesto el sol.

Eso se puso malo y por ahí mataron una vez un poco de gente. (...) pero cogimos miedo porque no se sabía cuál era cuál y eso mataban al que fuera por cualquier cosa. (...) Eso por allá se puso que llegó un poco de gente rara; uno ya no conocía a nadie, empezaron a matar gente sin uno saber porqué era (...). (GF1LR)

Las mujeres que han participado en los grupos focales confiesan haberse sentido amenazadas, desprotegidas y en un peligro inminente. Sus vidas sufren cambios bruscos e indeseables: actividades cotidianas como levantarse a las 4 de la mañana, montarse en un caballo y salir a ordeñar el ganado se vuelven misiones imposibles y en muchas ocasiones, suicidas. A partir de las 5 o 6 de la tarde los dueños de las fincas colocaban las trancas a sus portones, las tiendas cerraban y niños y adultos se refugiaban en sus casas.

Todo, todo cambió. (...) Cambió las costumbres porque de acostarse, por decir uno, a las ocho, a las nueve de la noche, hasta eso de las seis, adaptarse uno es maluco. Y hacé' lo que ellos dijeran. (...) Y los niños, que no hubiera niños en la calle, todos tenían que estar en la casa a toda hora del día. Entonces nada de lo que viéramos podíamos hablarlo, decirlo. Nada. (GF4S)

Eso no solo lo hacían por salvaguardar sus vidas, sino porque en algunos pueblos los grupos guerrilleros habían reunido previamente a la comunidad para informarles sobre las reglas que desde ese momento regirían en la zona. El sobresalto y la preocupación se apodera de las familias; los tiros y los combates entre grupos armados se convierten en sonidos familiares que acompaña muchas noches 
en vela. Con el paso del tiempo se fue generando un clima de desconfianza y miedo que poco a poco fue quebrando el tejido social, dividiendo a las personas y a las familias, destruyendo los modos de vida sostenidos por las pertenencias y las relaciones interpersonales, destruyendo las redes sociales de apoyo y minando la percepción subjetiva de bienestar que se asienta en tener una casa, alimento suficiente y contar con el respaldo de la familia y los vecinos.

(...) es que uno vivía, quedaba uno como nervioso. A uno le quedaba como el sobresalto siempre. Yo cuando iba llegando la noche yo ya me sentía asustada. Yo vivía asustada siempre allá en el pueblo. Imagínese que nosotros vivíamos en una finca que le decían El callejón de los muertos, porque a todos los que mataban los tiraban ahí, y el marido mío que a veces sacaba leche y se encontraba con muertos ahí. Imagínese cómo vivía uno. (GF3S)

Claro, allá uno no confiaba en nadie. Solamente en Dios. (...) Sí, porque uno ya no sabía ni quién era quién, porque había mucha gente que no era de confianza. (GF3S)

(...) Uno piensa tantas cosas porque uno vives es asustao'; cómo le diré, como temeroso, como desconfiao' de la gente, y uno no quiere da' papaya y que lo pillen por ahí. Uno siempre vive desconfiao' de la gente. (GF1LR)

Ante este estado de cosas, carentes de una perspectiva de solución y abandonados por completo a su suerte por parte de los poderes públicos, en muchos casos en estrecha connivencia con alguno de los grupos violentos (los paramilitares), se impone la decisión más razonable, la de rendirse a la evidencia (a las amenazas de los actores armados) y salir de aquellos laberintos de muerte para salvar la propia vida y la vida de los seres queridos. En la mayoría de los casos, las personas desplazadas deciden ir a sitios donde tienen familia, preferiblemente alejados de sus lugares de origen.

Y exacto, pero cuando ya empezaban a matar, que mataban un vecino aquí, que mataban otro vecino acá, ya uno se sentía como acorralado, y no sé que más le tocaba a uno que dejar lo que tenía y venirse, porque igual si no lo hubiéramos hecho nos hubieran matado por (...) iajá! La mayoría de los que querían seguir insistiendo de quedarse ahí, pues (...) los mataron iya! Y pues uno se sintió obligado a salir, porque no quería que uno que de pronto le fuera a pasar a uno lo que le pasó al vecino (...). (GF3LR)

Yo tenía una prima aquí y ya ella me había dicho varias veces: “Ay no, que esto [el pueblo] está malo!, iporqué no te vienes con los pelaos?' Y yo en ese momento estaba loca que no hallábamos pa' onde' cogé', y si nos quedábamos en Cesar de pronto nos encontraban rápido. Entonces llamamos a la prima y ella nos dijo: 'véngase pa' acá que acá nosotros los ayudamos. (GF3S)

Pero esa decisión se cobra un alto precio emocional. Muchas de las mujeres que han participado como co-investigadoras en estos estudios confiesan que a partir del desplazamiento, e incluso antes, son incapaces de tener un sueño reparador y presentan episodios de sueño interrumpido por pesadillas y recuerdos de los acontecimientos que presenciaron y sufrieron durante la etapa de la violencia. Eso les hace permanecer en estado de alerta, prevenidas, temerosas y con episodios frecuentes de re-experimentación, activación y evitación que siguen los cánones del TETP.

Yo, cuando salí, me dio mucha tristeza. Este (...), dejarlo todo. Las amistades que ya uno tenía allá, y dejar todo allá para empezar una nueva vida. (GF4LR)

Aunque ya se nos ha ido un poco, uno todavía se siente el temor, a veces cuando pasan por ahí repartiendo unos papeles, los panfletos que le dicen, como son de esa gente, uno se pone temeroso, se pone nerviosos con eso. Todavía uno se queda con ese temor, y a veces que él [el esposo] se demora en la calle con el carrito del raspao' y son por ejemplo las siete y él no ha venido, iuy!, ya otra vez me da el miedo. Él a veces me encuentra llorando, preocupada y con miedo. Entonces los pelaos como me ven así, ellos también se ponen a llorá'. (GF3LR) 
Yo quiero olvidarlo, yo quisiera (...) Eso que yo me siento quisiera apartarlo. Ya mi hijo tuvo cinco años; va a tener el once de agosto (...) de marzo. Cinco años [de asesinado], y para mí parece que hubiera sido ayer. (GF3LR)

\section{La vida en la ciudad}

Las condiciones del desplazamiento suelen ser, por lo general, estresantes en grado sumo; a las personas se les exige que abandonen su hogar y todas sus posesiones. Se les arranca de manera brusca y dolorosa de sus orígenes, se les amputa una parte importante de su vida personal y de su vida social, y se les envía a una aventura llena de incertidumbres y penurias. Salen de una situación de pobreza para instalarse en barrios donde brillan por su ausencia los servicios públicos, hay presencia de organizaciones delictivas, las condiciones de salubridad son mínimas, las fuentes de ingresos económicos son escasas, se hacinan en viviendas infectas en las que resulta imposible la privacidad y expuestas en muchos casos a las bruscas alteraciones del clima. La frecuente ayuda de familiares a duras penas es capaz de paliar estos problemas. Hemos pasado, pues, de la una pobreza digna a condiciones rayanas en la miseria (hace acto de presencia el hambre, una experiencia inédita para la inmensa mayoría de las desplazadas) donde encuentran su apoyo un sinfín de emociones negativas que tan perjudiciales resultan, hoy lo sabemos sobradamente, para la salud física y psicológica, más allá de consideraciones de género. El desplazamiento ha quebrado una filosofía de vida, una manera de ubicarse en el mundo (normas, costumbres y hábitos en diversos terrenos), ha roto el escenario de las relaciones interpersonales y de los vínculos sociales dejando a las personas inermes y solas frente a una realidad desconocida en la que además se las considera intrusas y advenedizas:

No salía mucho (...) No porque no la conocía [la ciudad a la que llegó] y que me daba miedo también de si salía y yo no sabía para donde iba a coger y me perdía ya. (GF1S)

A mí me costó mucho trabajo; me costó mucho. No teníamos cómo pagar un arriendo y trabajando de a poquito (...) Pero definitivamente lo más duro que me ha dado fue cuando quedamos desamparados porque se me cayó la casita de tablas de allá. Yo me sentía mal y la gente llegaba y decía: 'iAy, niña, qué pobrecita!'. Y eso da nostalgia que le diga a uno así porque yo me sentía poquita cosa. (GF3S)

No, todo, mija, todo el cambio de aquí fue. (...) Yo lo sentí todo, sobre todo la alimentación. Uno allá se alimenta sanamente y por bastante; en cambio aquí no. Uno tiene que medir, medir las cosas, porque uno no va a comer así (...) por lo menos uno allá comía. (...) En cambio aquí uno tiene que comer dos libras de yuca, tres libras de yuca, pero allá no. (...) Allá poníamos a cocinar una olla de yuca que sobrara la yuca. (...) Aquí no (...) Entonces todo, todo. A mí se me ha hecho difícil todo. (GF1LR)

Nosotros llegamos aquí sin un peso. Nosotros sacábamos limitadamente para comer, porque no había para nada más. Mis hijas no tenían ropa; o sea, cositas todas feítas, viejitas, rotica. No tenían. Terrible. Entonces pasamos lo peor. (GF2S)

A pesar del panorama tan desolador al que se enfrentan, poco a poco se logran adaptar a la vida en la ciudad, va disminuyendo el nivel de sus temores, empiezan a conocer cómo funciona el contexto, cuáles son sus demandas y cómo deben desenvolverse en él. La ciudad empieza a cumplir funciones para ellas inesperadas: a) les transmite una seguridad vital de la que no gozaban en el campo: su vida y la vida de sus hijos corre mucho menos peligro; b) les da la oportunidad de encontrar un trabajo y de sentirse útiles aportando a la economía familiar; c) les ayuda a olvidar el pasado; d) les ofrece posibilidades de educación, de formación, de empoderamiento; e) ofrece a sus hijos oportunidades insospechadas en el medio rural y $\mathrm{f}$ ) les ayuda a ver determinadas realidades (el maltrato y la violencia por parte de la pareja) desde una nueva perspectiva:

Aquí, con el tiempo, ya uno se va sintiendo diferente, y cuando nos dieron la ayuda ya nosotros pudimos comprar el carro de raspao' y salimos de esa casita de tabla, y aunque no tenemos plata porque yo cuando 
voy a las reuniones [del programa de intervención], yo me vengo a pie, ya gracias a Dios uno se siente ya mejor, ya conocemos más gente y yo digo 'palante es pa allá.' Ya yo, gracias a Dios, me siento como en una nueva vida. Nos han ayudado bastante y bueno con el favor de Dios ahí vamos saliendo adelante (...). (GF3S)

Yo estoy ocupada aquí, en la tienda, despachando. Atiendo a las personas, converso con las personas, y a uno eso se le olvida [lo vivido durante la violencia], digo yo. Entonces ya no pienso tanto en eso. Yo digo que lo que me ha permitido seguir adelante ha sido trabajar, que hemos tenido juicio, eso nos ha ayudado bastante. Psicológicamente, económicamente, moralmente nos ha ayudao'. (GF1LR)

\section{Volver a empezar}

La situación de desplazamiento, indeseable desde cualquier punto de vista, ha dado, de manera especial a las mujeres, un impulso para volver a empezar. Algunas de las participantes en los grupos focales llegaron a confesar que, a pesar de los graves inconvenientes, a ellas les ha convenido el desplazamiento, les ha resultado positivo; fue una decisión acertada no solo porque sorteó los peligros de la violencia, sino porque les ha abierto nuevos caminos. La vida en la ciudad les ha mostrado una realidad donde los inconvenientes van de la mano de oportunidades nunca antes imaginadas, donde es posible aprender a tener esperanza, donde pueden hacer planes para el futuro, donde cabe la posibilidad de plantearse un proyecto de vida para ellas, y sobre todo para sus hijos, y donde es posible reconstruir redes sociales de apoyo como las que había en el entorno rural ("aunque muchas veces no me puede ayudar, me escucha y sé que no se lo va a contar a nadie"). Junto a la evocación nostálgica de lo que dejaron en el amargo camino de la violencia (las pérdidas) se encuentra una mirada llena de esperanza hacia el futuro (las oportunidades).

Yo no sé si [el cambio en su vida se ha debido] al desplazamiento. Este, no sé cómo llamarlo si es tan malo, pero a mí me ha convenido porque he visto cosas buenas y bien en el hogar. Todo eso desde que llegamos acá. (...) Yo pienso que todo lo que yo hice fue lo mejor que pude hacer, porque yo, de haberme quedado allá quién sabe qué hubiera sido. Yo creo que peor. No sé. Como que yo creo que lo mejor que pude haber hecho es salir. (GF4S)

Me gustaría cambiar, ieh? Sacar a mis hijos adelante y que más adelante sean unos profesionales. Y cambiar, cambiar (...) Mis anhelos son que mis cuatro hijos sean unos profesionales, que ellos estén bien, que Dios me los conserve así, que no vayan a tener malas compañías, que sean unos muchachos respetuosos, que sean obedientes (...) tantas cosas. (GF1S)

Para mis hijos yo pido lo mejor, lo mejor, como que yo no entre a una universidad, pero que yo no termine un bachillerato, pero que lo terminen ellos. Para mis hijos pido lo mejor. Lo mejor aspiro para mis hijos. (GF3LR)

A las mujeres de nuestros grupos focales se les invitó a soñar despiertas. Una de ellas sueña con aprender a leer, a escribir y a coser. Otra con abrir un negocio de venta de comidas; otra quiere estudiar Secretariado, otra aprender estética para abrir un salón de belleza. Son muchas las que sueñan en conseguir un empleo que les ayude a brindarles un mejor futuro a sus hijos. Solo una soñó con volver a su lugar de origen.

Cuando yo estaba en el pueblo aspiraba a eso, y decíamos vamos a ver cómo nos conseguimos una tierra y criamos nuestros animales. Eso era lo que yo aspiraba. Y de pronto, aquí en la ciudad, yo quiero es vivir de mi negocio y vivir de otra forma, de modo que cuando venga un familiar de pa' allá o un amigo y yo tenga como recibirlo y diga 'no Yolanda es otra, ella se fue pa' la ciudad y ahora la veo distinta. Esas son mis aspiraciones. (GF1S)

Me gustaría tener mi casa propia y una casa que esté, ajá, bien bonita, como una mujer sueña, porque me imagino que tú también soñarás en tener una casa bien bonita, tener todas las comodidades (...). (GF4LR) 
Paulatinamente, se va produciendo un modesto proceso de independencia económica, descubrimiento y fortalecimiento de capacidades personales de cuya posesión eran desconocedoras, y de autonomía (tomar decisiones e iniciar actividades por sí mismas) que les permite salir de los estrechos límites del presentismo, ser muy críticas con algunas decisiones tomadas en el pasado (haber iniciado tan temprano la vida en pareja), mirar hacia el futuro desde un nuevo planteamiento de vida, marcarse metas a corto y a largo plazo, mejorar su autoimagen y su autoestima, sentirse útiles para la familia consiguiendo, por ejemplo, días de planchado o trabajo en casas de familia para aportar a la economía familiar, comprar "cositas" necesarias para la casa o ahorrar para lograr construir en un terreno. Un paulatino y modesto proceso de emancipación que les conduce a confrontar la realidad mediante nuevas estrategias de afrontamiento que han ido incorporando a su vida:

Ahora que de pronto veo que ya estoy realizando una de las tantas cosas, de pronto no me veo ni todavía como que montada yo en una oficina mía, pero sí me veo un poco más arriba de lo que ahora estoy, de que anteriormente estaba. Me veo una mujer realizada que tiene sus metas, que tiene estrategias, que tiene sus ganas y que tengo una familia que me apoya. (GF2LR)

Yo lo hago por mi pelaíta [su hija]. Por ella. (...) Ya entonces son cosas, son metas, eso es lo que 'tamos dando ahora. Son metas que tengo y una de las metas [es] que ahora que estoy estudiando, que dije 'voy a estudiar nuevamente', me puse yo a pensar: perdí dos años de mi vida aparte de los que perdí con José Rafael, perdí dos años más de mi vida por no pensar bien. (GF2LR)

[Tengo] las ganas, las ganas de seguir, seguir adelante, tener algo propio, algo que brindarle a mis hijas más adelante. Las ganas que tengo de seguir. (...) Trabajando, juiciosa, de todo. Espero que se hagan realidad mis sueños. (GF2S)

Nosotras somos unas mujeres berracas (...) que no nos hemos dejado vencer. (...) Yo me le mido a lo que sea (risas). No importa, porque ya tengo una meta y quiero cumplirla. Yo no me, no me aguchento por nada. Pa'lante es pa'allá, me toque pasarlo como me toque. Pa'lante es pa'allá. (GF4S)

A veces, mientras estamos despiertos, no solo soñamos, sino que nos despertamos de alguna pesadilla. En medio de aspectos tan sombríos asociados al desplazamiento, es posible observar un cambio en la percepción que algunas mujeres tienen en la manera de valorar el maltrato de la pareja. Es posible atisbar un primer paso para romper el ciclo monótono de la violencia de género. Un paso que, junto a los que hemos mencionado en el transcurso de este epígrafe, sirve para reconstruir la identidad de estas mujeres desde parámetros claramente distintos a los que eran usuales en su vida campesina. El caso de Ludys (nombre ficticio) es paradigmático. Su marido siempre la trató mal:

Antes él daba pa' lo de la casa, y yo le tenía miedo. Yo sabía que me pegaba (...) A veces me olvidaba que tenía marido y me iba a jugar. A él le daba rabia. Cada vez que él se ponía bravo conmigo, yo convulsionaba. (...) En aquella época [antes del desplazamiento], aguantar y aguantar. No me podía quejar con nadie porque me echaban a mí las culpas, y ajá, dígame usted qué podría hacer yo. Aguantar, y a veces me encerraba a llorar. (GF1LR)

Durante su vida en el campo, por lo menos el esposo "cumplía con las cosas de la casa", pero desde que llegaron desplazados a la ciudad "se ha como desentendido de todo, no tiene que ver con nada y no se le puede decir es nada". A consecuencia de ello se toma la decisión de romper el círculo de la violencia.

Le dije: si eres tan hombre, pégame; ven y me pegas de una vez si es que eres tan macho (...) Siempre me pegaba por eso hasta el año antes pasado que cogió un palo pa' darme y le dije: 'mira, José, tú que me tocas y uno que se va pa' el cementerio y el otro para la cárcel, porque yo te mato. Desde esa vea no se ha atrevido nunca más. Fueron 36 años dándome (...) Desde el 23 de diciembre del año antes pasado no me pega. Ese día me le paré. (GFLR) 


\section{Discusión}

Los metanálisis y las revisiones llevados a cabo en los dos últimos años (American Psychological Association [APA], 2010; Bonnano, Brewin, Kaniastry \& La Greca, 2010; Furr, Comer, Edmunds \& Kendall, 2010; Masten \& Narayan, 2012) siguen aportando pruebas fehacientes (estadística, social y psicológicamente significativas) sobre un asunto de extraordinaria importancia teórica: ante un acontecimiento traumático, ser mujer en cualquier momento del ciclo vital es un factor de riesgo. Ante un mismo evento, los niveles de angustia, depresión, ansiedad, síntomas de estrés postraumático y TEPT propiamente dicho son más elevados en las mujeres que en los hombres. El metanálisis de Tolin y Foa (2006) concluye que el rango diferencial de sufrir un TEPT entre hombres y mujeres es de 1.98 , tanto ante eventos naturales como ante acontecimientos causados por la mano del ser humano.

Lo que es común a muchos de los datos procedentes de contextos geográficos y culturales tan distintos como los que se han señalado a lo largo de este artículo son tres condiciones de un indudable alcance teórico: a) se trata, en primer lugar, de mujeres; b) que están en situación de pobreza y c) pertenecen a culturas o subculturas dominadas por una ancestral inequidad, que deviene frecuentemente en violencia, en las relaciones de género. Tres condiciones sociales a las que es común la marca inconfundible de la pertenencia categorial que es, por encima de cualquier otra consideración, una marca psicosocial (Tajfel, 1984).

La pobreza duele, podemos leer en el primer volumen del informe que el Banco Mundial dedica a este tema; "las personas pobres sufren dolor físico como consecuencia de comer poco y trabajar muchas horas; dolor emocional a raíz de las humillaciones diarias que ocasiona la dependencia y la falta de poder y dolor moral por verse forzadas a hacer elecciones; por ejemplo, si utilizan fondos limitados para salvar la vida de un miembro de la familia que está enfermo, o para alimentar a sus hijos" (Narayan, 2000, p. 3). Cuando a la pobreza se le añade el género, el dolor se multiplica, y si estas dos condiciones se ven acompañadas por la pertenencia a una minoría racial o cultural (según Rodríguez, Alfonso \& Cavalier, 2009, el 22.5\% de la población desplazada está compuesta por afrocolombianos) el riesgo para la salud física y mental se vuelve endémico no solo en comparación con los hombres, sino con la población general, debido, entre otras razones, a los altos índices de exclusión, discriminación y violencia que suelen rodear estas condiciones de vida y a las que están especialmente expuestas las mujeres (Belle, 1982, 1990), no importa que sean afroamericanas en Estados Unidos o desplazadas en Colombia. En el punto 106 del Auto 005 de la Corte Constitucional colombiana del 16 de enero de 2009 se dice de manera expresa que "el desplazamiento forzado obliga al pueblo afrocolombiano a asumir el nuevo e inhóspito entorno en un proceso de readaptación de sus prácticas culturales y de apropiación de otras formas de vida urbana, y de franca resistencia a las formas abiertas y sofisticadas de racismo y de exclusión social como grupo étnico" (citado en Rodríguez, Alfonso \& Cavalier, 2008, p. 222).

La interacción de estas tres condiciones (género, pobreza y pertenencia a una minoría racial, étnica o cultural) llena la vida de cientos de millones de mujeres de experiencias amargas y de emociones negativas debido a una fatal combinación de eventos estresantes de vida (la violencia entre ellos), escasos recursos económicos y sociales para hacerles frente, pobres o inadecuadas estrategias de afrontamiento y actitudes de humillación, rechazo, exclusión y discriminación a las que se ven expuestas (Gallo \& Matthews, 2003; Krieger, 1999; MacDonald \& Leary, 2005; Pascoe \& Richman, 2009).

En este contexto, la violencia ocupa un lugar preferente. "La incidencia de la violencia contra la mujer en los conflictos armados, en particular la violencia sexual, inclusive la violación, está siendo cada vez más reconocida y documentada" (Naciones Unidas, 2006, p. 51). Colombia no es una excepción: "Los consultantes de los servicios de salud mental de MSF con frecuencia mostraron problemas de adaptación y un mayor grado de exposición a otros tipos de violencia (intrafamiliar, sexual o social), como suele ocurrir en contextos de conflicto armado" (Médicos Sin Fronteras, 
2010, p. 9). En una reciente investigación llevada a cabo en la Costa Caribe colombiana con 224 hombres desmovilizados, Ávila-Toscano y Cogollo (2011) señalan que "el 82.1\% de los participantes indica tener episodios de violencia contra sus parejas, siendo las agresiones psicológicas las más frecuentes mediante acciones como el uso de violencia verbal y la falta de cooperación" (p. 100). La Encuesta Nacional sobre Violencia contra la Mujer en Estados Unidos (National Violence Against Women Survey) pone igualmente de manifiesto que son ellas las más expuestas a la agresión interpersonal, especialmente cuando al género se unen la pobreza y un menor nivel educativo. Tomados en su conjunto, los resultados de esta encuesta no apoyan la hipótesis de una mayor vulnerabilidad de las mujeres; esa aparente vulnerabilidad femenina es simplemente producto de la exposición de género (gender-linked exposure) (Pimlott-Kubiat \& Cortina, 2003, p. 531), claramente mediada por lo que social y culturalmente rodea al hecho de ser mujer, de suerte que en vez de hablar de "vulnerabilidad femenina", hablaríamos de "vulnerabilidad situacional" (p. 537), una idea que nos recuerda y nos remite a la crítica que Martín-Baró (1998) hiciera a la "sutil psicologización" del síndrome fatalista: "los datos disponibles no confirman la existencia de una subcultura propia de los pobres que perpetúe su situación como mecanismo funcionalmente autónomo respecto al sistema global” (p. 89), sino la existencia de una recia estructura social a la que se adaptan las personas ante la imposibilidad de revertirla, porque cuando encuentran la posibilidad de hacerlo, se pone claramente de manifiesto que "no es voluntad, ni deseo, ni empuje, ni siquiera flexibilidad lo que falta a muchos marginados", sino "oportunidades sociales mínimas" para lograrlo (Martín-Baró, 1998, p. 87).

La prueba más convincente nos la ofrecen las mujeres que han participado en este estudio cuando encaran, con la decisión y energía que hemos visto en el último epígrafe ("Volver a empezar"), su propio futuro y el de sus hijos, cuando sueñan despiertas sobre lo que quieren para sus vidas y para las vidas de sus seres más queridos. La situación de desplazamiento ("la vida en la ciudad") plantea un nuevo escenario que implica "el cuestionamiento de los pilares sobre los que las mujeres habían concebido su forma de existir, su identidad de género en la medida en que se hace ineludible la adopción de nuevos roles en la esfera pública, en la construcción o reconstrucción de redes sociales, la generación de ingresos, la protección y responsabilidad por la familia" (Duque, 2000, p. 175). La adopción de nuevos roles y, desde ahí, la paulatina reconstrucción de una nueva identidad de género ha sido señalado como un punto de inflexión en la peripecia biográfica de la mujer en situación de desplazamiento (Arias \& Ruiz, 2000) y en la situación general de la mujer en situación de pobreza. En estos contextos, el hombre ha pasado "de sostén de la familia a lastre", mientras que la mujer se convierte en el "nuevo sostén de la familia" (ver Narayan, 2000, pp. 182-193). En el caso del desplazamiento en Colombia ocurre prácticamente lo mismo: los hombres tienen muchas más dificultades para encontrar un empleo, para adaptarse a la vida en la ciudad, el desempleo les afecta más que a las mujeres y ello les aparta de su tradicional rol de proveedores dañando de manera considerable su autoestima, su dignidad y, en la medida correspondiente, su masculinidad. Su poder indiscutible empieza a resquebrajarse (Meertens, 2004; Tovar \& Pavajeau, 2010; Viveros, 2002). En una reciente investigación llevada a cabo con ayuda de entrevistas semiestructuradas en profundidad y grupos focales de víctimas del Oriente Antioqueño (Argelia, La Unión, Granada, etc.) y Córdoba, Juan David Villa llega a la misma conclusión: "el afrontamiento a la situación de violencia se convirtió en una oportunidad para realizar una transformación de las relaciones y los roles de género, de tal manera que, desde el punto de vista de las mujeres, las transformaciones vividas a la fuerza han sido una oportunidad para romper con algunos ejercicios de dominación y sometimiento que han traído una nueva forma de estructurar las familias, un cambio en las relaciones con los hombres, y han abierto la puerta a las mujeres para la participación en el espacio público" (Villa, 2012, p. 233).

Pero esto no solo ocurre en Colombia, lo podemos ver también en Jamaica, Argentina, Bangladesh, Egipto, Etiopía, etc. El Informe del Banco 
Mundial sobre la pobreza nos ofrece numerosos ejemplos: en todo el mundo "las mujeres están buscando activamente la equidad y cambios significativos en los papeles e identidades de género" (Narayan, Chambers, Shah \& Petesch, 2002, p. 117). Y hay situaciones que guardan un gran parecido entre sí a pesar de la distancia geográfica que las separa: en una comunidad de Brasil, "las mujeres incluyen la decisión de separarse del marido y presentar quejas acerca del comportamiento agresivo de los hombres como las dos decisiones más importantes que pueden adoptar. Añaden que no habrían tenido el valor de llevar a cabo estas decisiones en el pasado" (Narayan et al., 2002, p. 118), como les ocurre a las mujeres que han actuado como co-investigadoras en nuestros estudios.

Pese a todo, sienten una sincera añoranza por la comunidad, por la tranquila y apacible vida en el campo, como la sentían aquellas ingentes masas de campesinos europeos que dieron los primeros pasos de la Revolución Industrial. La añoranza de la comunidad es una de las "ideas-elementos" más recios en la formación del pensamiento sociológico (Nisbet, 1969). Pero es necesario añadir de inmediato que entonces, como ahora, comunidad significa "intimidad personal, profundidad emocional, compromiso moral, cohesión social y continuidad en el tiempo" (p. 71), y confianza, participación en actividades comunes, reciprocidad, apoyo; en una palabra, vínculos afectivos tan decisivos para nuestra salud física y mental, porque "lejos de ser meras convenciones sociales, estas relaciones influyen de modo fundamental en la biología a lo largo de toda nuestra vida, al tiempo que son influidas por ella, y lo hacen de manera que pueden proteger o dificultar nuestra salud y nuestro bienestar" (Taylor, 2000, p. 21). Eso es lo que añoran las mujeres que han participado en este estudio. No tanto volver a la vida en el campo, sino recuperar los lazos vitales y las relaciones de confianza y reciprocidad que habían caracterizado su vida anterior.

En una arriesgada maniobra teórica magistralmente resuelta, Durkheim (1928) había puesto la capacidad de integración en el punto de mira del suicidio egoísta; este se origina porque la sociedad carece de mecanismos para acoger, cuidar, defen- der y mantener unidos a sus miembros. La única respuesta "es dar a los grupos sociales bastante consistencia para que mantengan más firmemente al individuo, y que éste, a su vez, se sostenga unidos a ellos" (p. 418). La des-integración social es percibida como uno de los principales problemas del desplazamiento por parte de las mujeres que han participado como co-investigadoras en este estudio. En investigaciones llevadas a cabo con este mismo colectivo (hombres y mujeres adultas) ayudándonos en este caso de una metodología cuantitativa (aplicación de escalas de bienestar), hemos detectado una clara afectación en todas y cada una de las cinco dimensiones del bienestar social, entre las que se encuentra, de manera primordial, la integración, de suerte que "las personas desplazadas no solo evidencian en sí mismas la presencia del trauma modificando la percepción que tenían de sí y de sus capacidades para hacerle frente, sino que proyectan esa incapacidad personal en sus relaciones con los otros" (Abello et al., 2009, p. 467).

Ahora bien, para hablar con más propiedad sobre las diferencias de género en la experiencia traumática, este estudio hubiera necesitado de una muestra de hombres. Esta es una de sus limitaciones, pero no la única. También se debería haber tomado en consideración el tiempo transcurrido desde el desplazamiento, por entender que se trata de una variable que puede afectar al proceso de adaptación a la vida en la ciudad, a romper con determinados esquemas y pautas de relación previas y a plantearse metas futuras. Aunque casi todas las co-investigadoras en este estudio han contado con ayuda familiar para el desplazamiento y su posterior asentamiento en la ciudad, el apoyo recibido es muy diverso y ello puede estar afectando a la toma de determinadas decisiones que se consideran imprescindibles.

\section{Referencias}

Abello, R., Amarís, M., Blanco, A., Madariaga, C., Manrique, K., Martínez, M., et al. (2009). Bienestar y trauma en personas adultas desplazadas por la violencia política. Universitas Psychologica, 8(2), 455-470. 
Alto Comisionado de Naciones Unidas para los Refugiados (2011). Tendencias globales 2011: un año de crisis. Ginebra: Autor.

Alejo, E., Rueda, G., Ortega, M., \& Orozco, L. (2007). Estudio epidemiológico del trastorno por estrés postraumático en población desplazada por la violencia política en Colombia. Universitas Psychologica, 6(3), 623-635.

American Psychiatric Association (2002). DSM-IV-TR. Manual diagnóstico y estadístico de los trastornos mentales. Barcelona: Masson.

American Psychological Association (2010). Resilience and recovery after war: Refugee children and families in the United States. Washington, DC: Autor.

Amarís, M. (2012). Modelo analítico de las relaciones funcionales de las estrategias de afrontamiento familiar, funcionamiento familiar, la inteligencia social y de las estrategias de afrontamiento individual con respecto a la salud mental y las cogniciones postraumáticas en los jóvenes desplazados por la violencia sociopolítica. Tesis Doctoral, Universidad del Norte, Barranquilla, Colombia.

Arias, F., \& Ruiz, S. (2000). Impacto psicosocial del desplazamiento forzado en jóvenes. Construyendo en Colombia nuevas formas de esperanza. En M. Bello, E. Martín \& F. Arias (Eds.), Efectos psicosociales y culturales del desplazamiento (pp. 181- 208). Bogotá: Universidad Nacional de Colombia

Aristizábal, E., \& Palacio, J. (2003). Subjetivización del acto de desplazarse y aspectos psicopatológicos relacionados con experiencias violentas. Investigación y Desarrollo, 11(2), 238-253.

Ávila-Toscano, J., \& Cogollo, L. (2011). Motivos asociados a la conducta violenta contra la pareja en hombres desmovilizados del conflicto armado. Investigación y Desarrollo, 19(1), 88-115.

Belle, D. (1982). Lives in stress: Women and depression. Beverly Hills, CA: Sage.

Belle, D. (1990). Poverty and women's mental health. American Psychologist, 45(3), 385-389.

Bello, M. (2004a). El desplazamiento forzado en Colombia: acumulación de capital y exclusión social. En M. Bello (Ed.), Desplazamiento forzado. Dinámicas de guerra, exclusión y desarraigo (pp. 19-30). Bogotá: Universidad Nacional de Colombia/ACNUR.
Bello, M. (Ed.). (2004b). Desplazamiento forzado. Dinámicas de guerra, exclusión y desarraigo. Bogotá: Universidad Nacional de Colombia/ACNUR.

Bello, M., Martín, E., \& Arias, F. (Eds.). (2000). Efectos psicosociales y culturales del desplazamiento. Bogotá: Universidad Nacional.

Bonanno, G., Brewin, C., Kaniastry, K., \& La Greca, A. (2010). Weighing the costs of disaster: Consequences, risks, and resilience in individuals, families and communities. Psychological Science in the Public Interest, 11(1), 1-49.

Castaño, B. (1994). Violencia sociopolitica en Colombia. Repercusión en la salud mental de las víctimas. Bogotá: Corporación AVRE.

Castillo, A. (2004). El desplazamiento como fenómeno socioeconómico ligado a la concentración del poder sobre la tierra. En M. Bello (Eds.), Desplazamiento forzado. Dinámicas de guerra, exclusión y desarraigo (pp. 155-162). Bogotá: Universidad Nacional de Colombia/ACNUR.

Conferencia Episcopal de Colombia (1995). Desplazados por la violencia en Colombia. Bogotá: Kimpres.

Consultoría para los Derechos Humanos y el Desplazamiento (1999). Desplazados. Huellas de nunca borrar. Casos de Bogotá y Soacha. Bogotá: CODEHS/ Arquidiócesis de Bogotá/Editorial Kimpres.

De Jong, K., van der Kam, S., Swarthout, T., Ford, N., Mills, C., Yun, O., et al. (2011). Exposure to violence and PTSD symptoms among Somali women. Journal of Traumatic Stress, 24(6), 628-634.

Creamer, M., Burgess, P., \& McFarlane, A. (2001). Post-traumatic stress disorder: Findings from the Australian National Survey of Mental Health and Well-Being. Psychological Medicine, 31(7), 1237-1247.

Duque, H. (2000). Mujeres en situación de desplazamiento. Una experiencia de reinvención social desde la perspectiva de género en contextos urbanos. En M. Bello, E. Martín \& F. Arias (Eds.), Efectos psicosociales y culturales del desplazamiento (pp. 173-180). Bogotá: Universidad Nacional de Colombia.

Durkheim, E. (1928). El suicidio. Madrid: Editorial Reus. Flores, M., Molina, V., \& Valle, C. (2010). Bienestar y trauma en lisiados y lisiadas de guerra afiliados a la Asociación de Lisiados de Guerra de El Salvador 
(ALGES), dieciocho años después del conflicto armado. Tesis de Grado, Departamento de Psicología, Universidad Centroamericana "José Simeón Cañas" (UCA), San Salvador.

Furr, J., Comer, J., Edmunds, J., \& Kendall, P. (2010). Disaster and youth: A meta-analytic examination of posttraumatic stress. Journal of Consulting and Clinical Psychology, 78(6), 765-780.

Gallo, L., \& Matthews, K. (2003). Understanding the association between socioeconomic status and physical health: Do negative emotions play a role? Psychological Bulletin, 129(1), 10-51.

Giaconia, R., Reinherz, H. Silverman, A., Pakiz, B., Frost, A., \& Cohen, A. (1995). Traumas and posttraumatic stress disorder in a community population of older adolescents. Journal of the American Academy of Child and Adolescent Psychiatry, 34(19), 1369-1380.

Giacaman, R., Shannon, H., Saab, H., Arya, N., \& Boyce, W. (2007). Individual and collective exposure to political violence: Palestinian adolescents coping with conflict. European Journal of Public Health, 17(4), 361-368.

Grupo de Psicología Social Crítica (2010). Del dolor a la propuesta. Voces del Panel de Víctimas. Revista de Estudios Sociales, 36, 114-125.

Kessler, R., Sonnega, A., Bromel, E., Hughes, M., \& Neslon, C. (1995). Posttraumatic stress disorder in the National Comorbidity Survey. Archives of General Psychiatry, 52(12), 1048-1060.

Kolltveit, S., Lange-Nielsen, I., Mousa, A., Dyregrov, A., Pallesen, A., Johnsen, T., et al. (2012). Risk factors for PTSD, anxiety, and depression among adolescents in Gaza. Journal of Traumatic Stress, 25, 164-170.

Krieger, N. (1999). Embodying inequality: A review of concepts, measures, and methods for studying health consequences of discrimination. International Journal of Health Services, 29(2), 295-352.

Krueger, K. (1991). El grupo de discusión. Guía práctica para la investigación aplicada. Madrid: Pirámide.

Las Dignas. (1996). Montañas con recuerdos de mujer. San Salvador: Autor.

Las Dignas. (1997). Y la montaña habló. Testimonios de guerrilleras y colaboradoras del FMLN. San Salvador: Autor.
López, J., \& Scandroglio, B. (2007). De la investigación a la intervención psicosocial: la metodología cualitativa y su integración con la metodología cuantitativa. En A. Blanco \& J. Rodríguez (Coords.), Intervención Psicosocial (pp. 557-606). Madrid: Pearson.

Martín-Baró, I. (1998). Psicología de la liberación. Madrid: Trotta.

MacDonald, G., \& Leary, M. (2005). Why does social exclusion hurt? The relationship between social and physical pain. Psychological Bulletin, 131(2), 202-223

Masten, A., \& Narayan, A. (2012). Child development in the context of disaster, war, and terrorism: Pathways of risk and resilience. Annual Review of Psychology, 63(1), 227-257.

Médicos Sin Fronteras (2010). Tres veces víctimas. Víctimas de la violencia, el silencio y el abandono. Bogotá: Autor.

Meeterns, D. (2004). Género, desplazamiento, derechos. En M. Bello (Ed.), Desplazamiento forzado. Dinámicas de guerra, exclusión y desarraigo (pp. 197-204). Bogotá: Universidad Nacional de Colombia/ACNUR.

Naciones Unidas (2006). Estudio a fondo sobre todas las formas de violencia contra la mujer (Informe del Secretario General, A/61/122/Add.1). New York: Autor.

Narayan, D. (2000). La voz de los pobres. iHay alguien que nos escuche? Madrid: Ediciones Mundi-Prensa.

Narayan, D., Chambers, D., Shah, M., \& Petesch, P. (2002). La voz de los pobres. Clamando por el cambio. Madrid: Ediciones Mundi-Prensa.

Neugebauer, R., Fisher, P., Turner, J., Yamabe, S., Sarsfield, J., \& Stheling-Ariza, T. (2009). Post-traumatic stress reactions among Rwandan children and adolescents in the early aftermath of genocide. International Journal of Epidemiology, 38(4), 1033-1045.

Nisbet, R. (1969). La formación del pensamiento sociológico (Vol. 1.). Buenos Aires: Amorrortu.

Norris, F., Foster, J., \& Weissharr, D. (2002). The epidemiology of sex differences in ptsd across developmental, societal, and research contexts. En R. Kimmerling, P. Ouimette \& J. Wolfe (Eds.), Gender and PTSD (pp. 3-42). Nueva York: The Guilford Press. 
Norris, F., Friedman, M., Watson, P., Byrne, C., Díaz, E., \& Kaniasty, K. (2002). 60,000 Disasters victims speak: Part I. An empirical review of the empirical literature, 1981-2000. Psychiatry, 65(3), 207-239.

Norris, F., Murphy, A., Baker, C., Perilla, J., Gutiérrez F., \& Gutiérrez, J. (2003). Epidemiology of trauma and posttraumatic stress disorder in Mexico. Journal of Abnormal Psychology, 112(4), 646-656.

Norris, F., \& Sloane, L. (2007). The epidemiology of trauma and PTSD. En J. Friedman, T. Keane \& P. Resick (Eds.), Handbook of PTSD. Science and practice (pp. 78-98). Nueva York: The Guilford Press.

Palacio, J., Abello, R., Madariaga, C., \& Sabatier, C. (1999). Estrés postraumático y resistencia psicológica en jóvenes desplazados. Investigación y Desarrollo, 1(10), 16-29.

Palacio, J., \& Sabatier, C. (2002). Impacto psicológico de la violencia política en Colombia. Salud mental y redes sociales en familias desplazadas en el Caribe. Barranquilla: Ediciones Uninorte.

Pascoe, E., \& Richman, S. (2009). Perceived discrimination and health. A meta-analitic review. Psychological Bulletin, 135(4), 531-554.

Pérez, L. (2004). Factores asociados al desplazamiento forzado en Colombia. En M. Bello (Ed.), Desplazamiento forzado. Dinámicas de guerra, exclusión y desarraigo (pp. 49-79). Bogotá: Universidad Nacional de Colombia/ACNUR.

Pimlott-Kubiat, S., \& Cortina, L. (2003). Gender, victimization, and outcomes: Reconceptualizing risk. Journal of Consulting and Clinical Psychology, 71(3), 528-539.

Proyecto Interdiocesano de Recuperación de la Memoria Histórica. (1998). Guatemala Nunca Más. I: Impactos de la violencia. Guatemala: Oficina de Derechos Humanos del Arzobispado de Guatemala.

Rodríguez, C., Alfonso, T., \& Cavelier, I. (2009). El desplazamiento afro. Bogotá: Universidad de Los Andes.

Rojas, J. (Ed.). (1993). Desplazamiento, derechos humanos y conflicto armado. Bogotá: Codhes.
Smith, P., Perrin, S., Yule, W., Hacam, B., \& Stuvland, R. (2002). War exposure among children from Bosnia-Hercegovina: Psychological adjustment in a community sample. Journal of Traumatic Stress, 15(2), 147-156.

Stein, M., Walker, J., Hazen, A., \& Forde, D. (1997). Full and partial posttraumatic stress disorder. Findings from a community survey. American Journal of Psychiatry, 158(9), 1114-1119.

Stewart, A., \& McDermott, C. (2004). Gender in Psychology. Annual Review of Psychology, 55(1), 519 544.

Tajfel, H. (1984). Grupos humanos y categorías sociales. Barcelona: Herder.

Taylor, S. (2000). Lazos vitales. De cómo el cuidado y el afecto son esenciales para nuestras vidas. Madrid: Taurus.

Tolin, D., \& Foa, E. (2006). Sex differences in trauma and posttraumatic stress disorder: A quantitative review of 25 years of research. Psychological Bulletin, 132(6), 959-992.

Tovar, C., \& Pavajeau, C. (2010). Hombres en situación de desplazamiento. Transformaciones de la masculinidad. Revista de Estudios Sociales, 36, 95-102.

Vázquez, N., Ibáñez, C., \& Murguialday, C. (1996). Mujeres montaña. Vivencias de guerrilleras y colaboradoras del FMLN. Madrid: HORAS.

Villa, J. (2012). El papel de la memoria colectiva en el empoderamiento colectivo. Tesis Doctoral, Universidad Pontificia de Comillas, Madrid, España.

Viveros, M. (2002). De quebradores y cumplidores: sobre hombres, masculinidades y relaciones de género en Colombia. Bogotá: Universidad Nacional.

Wilches, I. (2010). Lo que hemos aprendido sobre la atención a mujeres víctimas de violencia sexual en el conflicto armado colombiano. Revista de Estudios Sociales, 36, 86-94.

Yáñez, S. (2010). Memoria histórica y derechos humanos. Un camino de apoyo psicosocial después del conflicto armado en El Salvador. Tesis doctoral, Universidad del País Vasco, España. 
